\title{
SALINITY GRADIENT MEIOBENTHOS DISTRIBUTION ON THE RAZDOLNAYA RIVER'S ESTUARY
}

(C) 2018

Milovankina Alexandra Alexandrovna, postgraduate student of Ecology Department

Fadeeva Natalia Petrovna, doctor of biological sciences, professor of Ecology Department

Far Eastern Federal University (Vladivostok, Russian Federation)

Chertoprud Elena Sergeevna, candidate of biological sciences,

leading researcher of Hydrobiology Department; leading engineer of Synecology Laboratory

Lomonosov Moscow State University (Moscow, Russian Federation);

A.N. Severtsov Institute of Ecology and Evolution (Moscow, Russian Federation)

Abstract. The paper studies salinity gradient meiobenthos distribution based on the results of the benthic surveys of the Razdolnaya estuary (the Sea of Japan, Amursky Bay). The density was increased with salinity growth on the Razdolnaya River's estuary. Meiobenthos was comprised by 8 taxonomic groups (Nematoda, Copepoda, Ostracoda, Oligochaeta, Mollusca, Amphipoda, Polychaeta и Chironomidae) with the dominance of nematodes. Most of meiobenthic species are presented by marine euryhaline species and registered throughout the Razdolnaya River's estuary. Fresh water species Dorylaimus chassanicus, Hofmaenneria gratiosa, Theristus brevisetosus and nematodes of the genera Paradontophora, widespread on estuaries of Far East of Russia, were dominated in meiobenthos in oligohaline zone of estuary; Monhystrella sp. Oncholaimium japonicum, Anoplostoma cuticularia, Daptonema inversum and Harpacticoid Copepods Remanea naksanensis, Onychocamptus mohammed, Huntemannia biarticulatus, Halectinosoma sp. were dominated in mesohaline zone. Nematode community are changed by zones throughout the estuary: Paradontophora genera are dominated in freshwater and olihaline zones, as well as freshwater species (Dorylaimus chassanicus, Hofmaenneria gratiosa. Theristus brevisetosus) were presented; Monhystrella sp. are dominated and freshwater spicies are decreased in the number at the mesohaline zone; Paracanthonchus macrodon, Oncholaimium paraolium, Sabatieria finitima, Dorylaimopsis peculiaris and S. palmaris are dominated at the euhaline zone. The nematocenes of inner part of estuarine zone aren't characterized by specific species assemblage and consist of species typical for nematode community of shallow water and of marine zones.

Keywords: meiobenthos; free-living nematodes; nematocenes; harpacticoid copepods; taxonomic composition; biodiversity; estuary; salinity gradient; oligohaline zone; mesohaline zone; fresh water zone; everyhaline; species of fresh water genesis; species of marine genesis; density; biomass; distribution; Razdolnaya River; Sea of Japan.

\section{ИНТЕГРАЛЬНАЯ ОЦЕНКА ПЕРСПЕКТИВНОСТИ ИНТРОДУКЦИИ ПРЕДСТАВИТЕЛЕЙ РОДА DEUTZIA THUNВ. В ЮЖНО-УРАЛЬСКОМ БОТАНИЧЕСКОМ САДУ-ИНСТИТУТЕ УФИЦ РАН (Г. УФА)} (C) 2018

Мурзабулатова Фануза Кавиевна, младший научный сотрудник лаборатории дендрологии, лесной селекции и интродукции древесных растений

Южно-Уральский ботанический сад-институт Уфимского федерального исследовательского иентра РАН (2. Уфа, Российская Федераиия)

Шигапов Зиннур Хайдарович, доктор биологических наук, временно исполняющий обязанности председателя

Уфимский федеральный исследовательский центр РАН (2. Уфа, Российская Федераџия)

Аннотация. В работе представлены результаты интродукционного изучения видов, гибридов и сортов рода Deutzia Thunb. коллекции Южно-Уральского ботанического сада-института (г. Уфа). Коллекция дейций является одной из наиболее крупных среди декоративных кустарников в ботаническом саду. Объектами исследований являлись 12 видов и 10 сортов дейций. Интродукционные исследования всех таксонов проводились в течение 10 лет (2007-2017 гг.). На протяжении всего периода наблюдений ежегодно оценивались следующие показатели: одревеснение побегов, зимостойкость, сохранение формы роста, побегообразовательная способность, прирост в высоту, генеративное развитие, возможные способы размножения в культуре. Анализ полученных данных показывает, что видовые таксоны отнесены к трем группам: вполне перспективные, перспективные и менее перспективные.

Максимально возможными показателями характеризуются 3 вида - D. amurensis, D. glabrata, D. parviflora. Все они могут быть рекомендованы для широкого применения в озеленении населенных пунктов Республики Башкортостан. В группе перспективных и менее перспективных оказались по 4 вида. Гибриды и сорта в коллекции относятся к трем группам: перспективные (II), менее перспективные (III), абсолютно непригодные (VI); в последней группе оказался один гибрид.

Ключевые слова: Deutzia; интродукция; устойчивость; перспективность интродукции; таксон; род; представитель; цветение; ассортимент; выбор; условия; интегральная оценка; выносливость; коллекционный фонд; фактор; шкала; декоративное садоводство; растение; показатель; степень; побег. 


\section{Введение}

Род Deutzia Thunb. включает более 60 видов и около 20 сортов; представители данного рода отличаются обильным и продолжительным цветением. В ландшафтном озеленении встречается в основном в районах с более мягкими климатическими условиями; для выращивания в средней полосе, в более суровых климатических условиях, следует подбирать таксоны, отличающиеся повышенной выносливостью [1-7].

Оптимальному выбору ассортимента декоративных растений для целей использования их в зеленом строительстве предшествует предварительная инте- гральная оценка перспективности интродукции растений [8-12].

Целью исследований являлась оценка перспективности и интродукционной устойчивости видов и сортов дейций, культивируемых в условиях ЮжноУральского ботанического сада-института - обособленного структурного подразделения УФИЦ РАН г. Уфы (Башкирское Предуралье), для последующего применения их в декоративном садоводстве и ландшафтном озеленении.

\section{Объекты и методы исследований}

Объектами исследований являлись таксоны дейций коллекции ботанического сада-института (табл. 1) [13; 14].

Таблица 1 - Коллекционный фонд рода Deutzia Южно-Уральского ботанического сада-института

\begin{tabular}{|c|c|c|c|c|}
\hline Таксон & Ареал & Место получения & $\begin{array}{l}\text { Дата по- } \\
\text { ступления }\end{array}$ & $\begin{array}{c}\text { Вид } \\
\text { материала }\end{array}$ \\
\hline D. $\times$ carnea (Lemoine) Rehder & - & БС г. Таллин, Эстония & 2009 & Семена \\
\hline D. crenata Siebold et Zucc. & Китай, Япония & ГБС г. Москва & 2011 & Черенки \\
\hline Deutzia discolor Hemsl. & Китай & ГБС г. Москва & 1986 & Саженцы \\
\hline D. gracilis Siebold et Zucc & Япония & Голландия & 2001 & Саженцы \\
\hline D. glabrata Kom. & $\begin{array}{l}\text { Корея, Китай, } \\
\text { Примор. край }\end{array}$ & ГБС г. Москва & 2006 & Семена \\
\hline D. $\times$ hybrida Lemoine 'Mont Rose' & - & Питомник, Голландия & 2001 & Саженцы \\
\hline D. $\times$ hybrida Lemoine & - & БС г. Люблин, Польша & 2006 & Семена \\
\hline D. $\times$ kalmiaeflora Lemoine & - & Питомник, Польша & 2001 & Саженцы \\
\hline D. $\times$ hybrida Lemoine 'Strawberry Fields' & - & Питомник, Голландия & 2001 & Саженцы \\
\hline D. longifolia Franch. & Зап. Китай & $\begin{array}{l}\text { БС Самарского гос. } \\
\text { университета }\end{array}$ & 2006 & Саженцы \\
\hline D. maximowicziana Makino & Япония & $\begin{array}{l}\text { БС г. Байройт, Герма- } \\
\text { ния }\end{array}$ & 2010 & Семена \\
\hline D. ningpoensis Rehd. & Китай & $\begin{array}{l}\text { БСУ г. Познань, } \\
\text { Польша }\end{array}$ & 2005 & Семена \\
\hline D. parviflora Bunge & Д.В., Китай & ГБС г. Москва & 1986 & Саженцы \\
\hline D. parviflora Bunge var. amurensis Regel & Д.В., Китай & ГБС г. Москва & 1986 & Саженцы \\
\hline $\begin{array}{l}\text { D. } \times \text { roseum 'Campanulata' } \\
\text { (Lemoine) Rehd }\end{array}$ & - & Питомник, Польша & 2007 & Саженцы \\
\hline D. scabra Thunb & Япония & $\begin{array}{l}\text { Собственная репро- } \\
\text { дукция }\end{array}$ & 2007 & $\begin{array}{l}\text { Укоренен- } \\
\text { ные черенки }\end{array}$ \\
\hline D. scabra Thunb. 'Plena' & Япония & ГБС г. Москва & 1986 & Саженцы \\
\hline D. scabra Thunb. 'Pride of Rochester' & - & Питомник, Польша & 2005 & Саженцы \\
\hline D. scabra Thunb. 'Pink Pompon' & - & Питомник, Польша & 2005 & Саженцы \\
\hline $\begin{array}{l}\text { D. schneideriana Rehder var. } \\
\text { laxiflora Rehder }\end{array}$ & Центр. Китай & БС г. Таллин, Эстония & 2009 & Семена \\
\hline D. vilmorinae E. Lemoine et Bois & Центр. Китай & ГБС г. Москва & 2006 & Семена \\
\hline
\end{tabular}

При интродукции лимитирующим фактором для инорайонных растений является их зимостойкость, которая определялась по шкале ГБС РАН [15]. Интегральная оценка перспективности интродуцентов формируется по 7 показателям жизнеспособности: степень одревеснения побегов, зимостойкость, сохранение формы роста, побегообразовательная способность, прирост в высоту, способность к генеративному развитию, возможные способы размножения в культуре.

Суммируя оценки по каждому показателю, согласно шкале перспективности, таксоны можно отнесены к шести группам: I - вполне перспективные (91-100 баллов); II - перспективные (76-90 баллов); III - менее перспективные (61-75 баллов); IV - мало перспективные; V - неперспективные (21-40 баллов); VI - абсолютно непригодные (5-20 баллов) [16; 17].
Дополнительно задействована шкала интродукционной устойчивости, предложенная Н.В. Трулевич, которая также является интегральным показателем биологической адаптации растений к новым условиям существования и разделяет растения по группам: высокоустойчивые - IV группа, устойчивые - III, слабоустойчивые - II, неустойчивые - I [18, c. 109-113].

\section{Результаты исследования и их обсуждение}

Результаты оценки жизнеспособности и перспективности интродуцированных таксонов, полученные в ходе фенологических наблюдений [19], представлены в таблице 2.

По полученным данным исследуемые виды по степени перспективности были разделены на три группы. К вполне перспективной (I группе) нами от- 

03.02.00 - общая биология Интегральная оценка перспективности интродукции представителей рода Deutzia Thunb...

несены D. amurensis, D. glabrata, D. parviflora, которые характеризуются высокими оценками по одревеснению побегов; к концу вегетационного периода побеги одревесневают на $100 \%$ и не повреждаются низкими температурами в зимний период [2-4]. По другим показателям (сохранение формы роста, побегообразовательная способность, прирост в высоту и генеративное развитие) эти таксоны также отмечены высокими оценками. По способу размножения данные таксоны получают 7 баллов, поскольку размножаются только при искусственном посеве.

Bo II группу (перспективные) включены D. discolor, D. ningpoensis, D. schneideriana var. laxiflora и D. vilmorinae, которые имеют высокие оценки по признакам сохранения формы роста, побегообразо- вательной способности, прироста в высоту, формирования семян, но у них низкие показатели по степени одревеснения побегов и зимостойкости [2; 3].

B III группе (менее перспективные) объединены D. gracilis, D. longifolia, D. crenata и D. scabra, имеющие высокие оценки по сохранению формы роста благодаря побегообразовательной способности и приросту в высоту. Последний вид из этой группы (D. scabra) имеет самое низкое количество баллов (68) по причине того, что в условиях Уфы он цветет, но семян не формирует. Кроме того, данный вид имеет низкие оценки по показателям одревеснения побегов и зимостойкости, а также по степени плодоношения и способам размножения (размножается только черенками).

Таблица 2 - Оценка перспективности интродуцированных таксонов дейций

\begin{tabular}{|c|c|c|c|c|c|c|c|c|c|c|}
\hline Таксон & ОП & Зим. & СФР & ПОС & ПВ & ГР & $\mathrm{BCP}$ & $\Sigma$ & ГПИ & КИУ \\
\hline D. amurensis & 20 & 25 & 10 & 5 & 5 & 25 & 7 & 97 & I & III \\
\hline D. glabrata & 20 & 25 & 10 & 5 & 5 & 25 & 7 & 97 & I & III \\
\hline D. parviflora & 20 & 25 & 10 & 3 & 5 & 25 & 7 & 95 & I & III \\
\hline D. discolor & 15 & 20 & 5 & 5 & 5 & 25 & 7 & 82 & II & II \\
\hline D. ningpoensis & 15 & 20 & 5 & 5 & 5 & 25 & 7 & 82 & II & II \\
\hline D. schneideriana var. laxiflora & 15 & 20 & 5 & 5 & 5 & 25 & 7 & 82 & II & II \\
\hline D. vilmorinae & 15 & 20 & 5 & 5 & 5 & 25 & 7 & 82 & II & II \\
\hline D. $\times$ magnifica & 15 & 20 & 5 & 5 & 5 & 25 & 3 & 78 & II & II \\
\hline D. $\times$ hybrida 'Strawberry Fields' & 15 & 20 & 5 & 5 & 5 & 20 & 3 & 73 & II & II \\
\hline D. crenata & 15 & 20 & 5 & 5 & 5 & 20 & 3 & 73 & III & II \\
\hline D. gracilis & 15 & 20 & 5 & 5 & 5 & 20 & 3 & 73 & III & II \\
\hline D. longifolia & 15 & 20 & 5 & 5 & 5 & 20 & 3 & 73 & III & II \\
\hline D. $\times$ kalmiaeflora & 15 & 20 & 5 & 5 & 5 & 20 & 3 & 73 & III & II \\
\hline D. maximowicziana & 15 & 20 & 5 & 5 & 5 & 20 & 3 & 73 & III & II \\
\hline D. $\times$ hybrida 'Mont Rose' & 15 & 20 & 5 & 5 & 5 & 15 & 3 & 68 & III & II \\
\hline D. scabra & 15 & 20 & 5 & 5 & 5 & 15 & 3 & 68 & III & II \\
\hline D. scabra 'Plena' & 15 & 20 & 5 & 5 & 5 & 15 & 3 & 68 & III & II \\
\hline D. scabra 'Pride of Rochester' & 15 & 20 & 5 & 5 & 5 & 15 & 3 & 68 & III & II \\
\hline D. rosea 'Campanulata' & 15 & 20 & 5 & 3 & 5 & 15 & 3 & 66 & III & II \\
\hline D. $\times$ hybrida 'Pink Pompon' & 15 & 20 & 5 & 3 & 5 & 15 & 3 & 66 & III & II \\
\hline D. $\times$ hybrida & 15 & 20 & 5 & 3 & 2 & 15 & 3 & 63 & III & II \\
\hline D. $\times$ carnea & 5 & 5 & 1 & 3 & 2 & 1 & 3 & 20 & VI & I \\
\hline
\end{tabular}

Примечание. ОП - одревеснение побегов; Зим. - зимостойкость; СФР - сохранение формы роста; ПОС побегообразовательная способность; ПВ - прирост в высоту; ГР - генеративное развитие; $B C P$ - возможный способ размножения в культуре; $\Sigma$ - сумма баллов; ГПИ - группа перспективности интродукции по П.И. Лапину и С.В. Сидневой [16]; КИУ - категория интродукционной устойчивости по Н.В. Трулевич [18].

Для оценки интродукционной устойчивости дополнительно использована шкала, разработанная Н.В. Трулевич [18], которая также является интегральной оценкой приспособленности растений к новым условиям существования. Ряд показателей в этой шкале совпадает с таковыми по П.И. Лапину и С.В. Сидневой [16].

Что касается гибридов и сортов, то для них методики по оценке интродукционной устойчивости видов по Трулевич мало пригодны, и нами была использована только методика перспективности интродукции Лапина и Сидневой. Согласно этому, гибриды и сорта в коллекции по баллам подразделяются на три группы: перспективные (II), менее перспективные (III) и абсолютно непригодные (VI). Во II группе высокие оценки у D. $\times$ magnifica и $D . \times$ hybrida 'Strawberry Fields'. B III группе оказались 2 гибрида и 5 сортов: D. $\times$ kalmiaeflora, D. $\times$ hybrida, $D . \times$ hybrida 'Mont Rose', D. × hybrida 'Pink Pompon', D. scabra
'Plena', D. scabra 'Pride of Rochester', D. rosea 'Campanulata'.

Единственный гибрид $D . \times$ carnea по всем признакам получила минимальные баллы и оказалась абсолютно неперспективной для интродукции в условиях Башкирского Предуралья. Для данного таксона характерна очень низкая побегообразовательная способность, отсутствие цветения и ежегодное обмерзание побегов. По этой причине $D . \times$ carnea отнесена нами к группе абсолютно непригодных для интродукции.

Результаты многолетнего интродукционного изучения таксонов дейций дают возможность сделать следующий вывод: 3 вида (D. parviflora, D. amurensis и D. glabrata) являются высокоустойчивыми и вполне перспективными для применения в ландшафтном озеленении в условиях Башкирского Предуралья. В группе перспективных и менее перспективных оказались по 4 вида. Гибриды и сорта в кол- 
лекции относятся к трем группам: перспективные (II), менее перспективные (III), абсолютно непригодные (VI); в последней группе оказался один гибрид.

\section{Список литературы:}

1. Заиконникова Т.И. Дейции декоративные кустарники (Монография рода Deutzia Thunb.). М.: Наука, 1966. 140 с.

2. Мурзабулатова Ф.К., Полякова Н.В. Зимостойкость дейций (род Deutzia Thunb.) в Башкирском Предуралье (г. Уфа) // Научные ведомости Белгородского государственного университета. Серия «Естественные науки». № 10 (153). Выпуск 23. Белгород, 2013. C. 51-53.

3. Мурзабулатова Ф.К., Рязанова Н.А. Фенологическая атипичность интродуцированных видов и сортов дейций (Deutzia Thunb.) // Известия Уфимского научного центра РАН. 2017. № 1. С. 46-48.

4. Мурзабулатова Ф.К. Сезонный ритм развития Deutzia amurensis (Regel) Airy-Schaw, при интродукции в Башкирском Предуралье [Электронный реcypc] // Hortus bot. 2017. T. 12, прил. II. - DOI: 10.15393/j4.art.2017.4169.

5. Мурзабулатова Ф.К. Первичные результаты интродукции видов и культиваров рода Deutzia Thunb. в Башкирском Предуралье // Интродукция растений: теоретические, методические и прикладные проблемы: материалы междунар. конф., посв. 70-летию Ботанического сада-института МарГТУ и 70-летию профессора М.М. Котова. 10-14 августа 2009 г., г. ЙошкарОла, Российская Федерация / под общ. ред. С.М. Лазаревой. Йошкар-Ола: МарГТУ, 2009. С. 63-66.

6. Соколова О.В. Род 4. Дейция, Жилистек - Deutzia Thunb. // Деревья и кустарники СССР. Т. 3. М.-Л.: Изд-во АН СССР, 1954. С. 152-162.

7. Славкина Т.И. Виды рода Дейция (Deutzia Thunb.), интродуцированные Ботаническим садом АН УзССР. Дендрология Узбекистана: Родовые комплексы крыжовника, смородины, дейции, катальпы // Дендрология Узбекистана. Т. 9. Ташкент: Фан, 1978. С. $74-125$.

8. Рязанова Н.А., Путенихин В.П. Интегральная оценка перспективности интродукции кленов в Башкирском Предуралье // Вестник Воронежского государственного университета. Серия: География. Геоэкология. 2010. № 2. С. 36-37.
9. Залывская О.С. Интегральная оценка перспективности интродукции растений // Вестник Брянского государственного университета. 2012. № 4-1. C. $83-86$.

10. Полякова Н.В. Интегральная оценка перспективности видов рода Syringa L. в коллекции Уфимского ботанического сада // Известия Уфимского научного центра РАН. 2016. № 3. С. 70-73.

11. Карпун Ю.Н. Основы интродукции растений // Сохранение и мобилизация генетических ресурсов в ботанических садах. Сочи, 2004. Вып. 2. С. 17-32.

12. Плотникова Л.С. Научные основы интродукции и охраны древесной растительности флоры СССР. М.: Наука, 1988. 264 с.

13. Каталог растений Ботанического сада-института Уфимского научного центра РАН. 2-ое изд., испр. и дополн. / В.П. Путенихин, Л.М. Абрамова, Р.В. Вафин, О.Ю. Жигунов, Л.Н. Миронова, Н.В. Полякова, 3.Н. Сулейманова, 3.Х. Шигапов; отв. ред. В.П. Путенихин. Уфа: АН РБ, Гилем, 2012. 224 с.

14. Мурзабулатова Ф.К. Структура коллекционного фонда и итоги первичной интродукции видов и культиваров рода Deutzia Thunb. в ботаническом саду г. Уфы // Биологическое разнообразие. Интродукция растений: материалы Четвертой междунар. науч. конф. СПб., 2007. С. 327-328.

15. Лапин П.И., Александрова М.С., Бородина Н.А. и др. Древесные растения Главного ботанического сада АН СССР. М.: Наука, 1975. 547 с.

16. Лапин П.И., Сиднева С.В. Оценка перспективности интродукции древесных растений по данным визуальных наблюдений // Опыт интродукции древесных растений. М.: Наука, 1973. С. 7-67.

17. Арестова Е.А. Интегральная оценка перспективности растений рода Sorbus L. в дендрарии НИИСХ юго-востока // Лесное хозяйство Поволжья. Саратов, 2002. Вып. 5. С. 98-102.

18. Трулевич Н.В. Эколого-фитоценотические основы интродукции растений. М.: Наука, 1991. 213 с.

19. Мурзабулатова Ф.К., Вафин Р.В., Путенихин В.П. Сезонный ритм развития представителей рода Deutzia Thunb. в Башкирском Предуралье // Научно-практический журнал «Вестник ИрГСХА». Выпуск 44, июль. Иркутск, 2011. С. 137-143.

\title{
INTEGRATED ASSESSMENT OF INTRODUCTION PROSPECTS OF DEUTZIA THUNB. GENUS REPRESENTATIVES IN THE SOUTH-URAL BOTANICAL GARDEN-INSTITUTE (UFA)
} (C) 2018

\author{
Murzabulatova Fanuza Kavievna, junior researcher \\ of Dendrology, Forest Tree Breeding and Introduction of Woody Plants Laboratory \\ South-Ural Botanical Garden-Institute of the Ufa Federal Research Centre of Russian Academy of Sciences \\ (Ufa, Russian Federation) \\ Shigapov Zinnur Khaidarovich, doctor of biological sciences, acting chairman \\ Ufa Federal Research Centre of Russian Academy of Sciences (Ufa, Russian Federation)
}

Abstract. The paper contains results of introduced study of species, hybrids and sorts of Deutzia Thunb. genus in
the South-Ural botanical garden-institute (Ufa). The collection of Deutzia is one of the largest among ornamental
shrubs in the botanical garden. The objects of researches were 12 species, 10 hybrids and sorts of Deutzia. Intro-
duced researches of all taxons were conducted within 10 years (2007-2017). Throughout the entire period of obser-
vations the following indicators were annually estimated: lignification of escapes, winter hardiness, preservation of a
form of growth, sprout-formation ability, a gain in height, generative development, possible ways of reproduction in
the culture. The analysis of the obtained data shows that specific taxons are belong to three groups: quite perspective,
perspective and less perspective. The greatest possible indicators characterize 3 species - D. amurensis, D. glabrata, 
D. parviflora. All of them can be recommended for broad application in gardening of settlements of the Bashkortostan Republic. Perspective and less perspective groups contained 4 species each. Hybrids and sorts in the collection belong to three groups: perspective (II), less perspective (III) completely unusable (VI); in the latter group contains one hybrid.

Keywords: Deutzia; introduction; stability; introduction prospects; taxon; genus; representative; flowering; assortment; selection; conditions; integral evaluation; endurance; collection fund; factor; scale; ornamental gardening; plant; index; degree; shoot.

\title{
УЧАСТИЕ ПОЧВЕННЫХ ВОДОРОСЛЕЙ И МХОВ В ФОРМИРОВАНИИ БИОЦЕНОЗОВ ОТВАЛОВ МИХАЙЛОВСКОГО ГОРНО-ОБОГАТИТЕЛЬНОГО КОМБИНАТА КУРСКОЙ МАГНИТНОЙ АНОМАЛИИ
}

(C) 2018

\author{
Нагорная Ольга Вячеславовна, кандидат биологических наук, \\ доцент кафедры экологии, садоводства и защиты растений \\ Курская государственная сельскохозяйственная академия имени И.И. Иванова \\ (2. Курск, Российская Федерация)
}

Головастикова Антонина Валентиновна, кандидат сельскохозяйственных наук, доцент кафедры товароведно-технологических дисциплин

Курский институт кооперации (филиал) Белгородского университета кооперации, экономики и права (2. Курск, Российская Федерация)

\begin{abstract}
Аннотащия. В статье представлены результаты исследований по изучению роли представителей отделов Algae и Bryophyta в сложении биоценозов отвалов лёссовидного суглинка и глины келловея различного возраста $(5,15,25$ лет) Михайловского горно-обогатительного комбината Курской магнитной аномалии. Рассмотрено участие почвенных водорослей и мхов как индикаторов изменения биоценоза в связи с особенностями литологической основы и возраста отвалов. Доказано, что сукцессионные изменения сообществ почвенных водорослей и мхов совпадают с сукцессионными изменениями фитоценозов отвалов в целом. Проведенные исследования показали, что первичными заселителями отвалов являются представители отдела синезеленые водоросли Суаnophyta. Они формируют моно-сообщество на 5-летних отвалах глины келловея и доминируют на 5-летних отвалах лёссовидного суглинка. Дальнейшее формирование устойчивого альго-сообщества, на всех типах исследуемых пород, идет по зональному типу. Первым из отдела моховидные Bryophyta отвалы заселяет Ceratodon purpureus (Hedw.). Он является доминантным видом и сохраняется на всех породах до 25-летнего возраста как наименее требовательный к субстрату. Далее формирование сообщества мхов идет по зональному типу и на лёссовидном суглинке, в среднем на 15 лет быстрее. Выявлено, что формирование водорослевых сообществ и ценозов мохообразных идет с разной скоростью на почвогрунтах отвалов. Рассчитано, что стабилизация ценозов водорослей требует около 19 лет на четвертичном лёссе и 32 года на глине келловея. Стабилизация сообщества мхов потребует около 35 лет на лёссе и около 70 лет на глине келловея.

Ключевые слова: КМА; Курская магнитная аномалия; Михайловский ГОК; Курская область; Algaе; Bryophyta; отвалы вскрышных пород; почвогрунты; лёссовидный суглинок; глина келловея; сингенетические сукцессии; ценозы; моховидные; почвенные водоросли; индикационные свойства; зональные почвы.
\end{abstract}

\section{Введение}

Михайловское месторождение железной руды, расположенное на северо-западе Курской области, одно из крупнейших в мире. Район Михайловского железорудного карьера располагается в южной части Среднерусской возвышенности. Зональными типами растительности района являются широколиственные леса и луговые степи.

Целью наших исследований было установление особенностей формирования отдельных компонентов биоценоза как показателей экологического состояния отвалов вскрышных пород Михайловского железорудного карьера КМА, с возможностью их рационального использования.

Одним из основных и наиболее ярких показателей состояния биоценоза является растительность, как эдификатор экологических условий и основной фактор, изменяющий эти условия. Важное значение в формировании биоценозов отвалов имеют почвен- ные водоросли и мхи, так как они являются основой любого биоценоза, и поэтому отклонения биохимических и физиологических реакций этих представителей низших и высших растений, весьма чувствительных к изменению условий среды, и могут служить индикаторами его состояния.

Почвенные водоросли, как компонент биоценоза, являются важной составной частью почвенной биоты и играют важную роль в образовании устойчивого биолого-почвенного сообщества. Они активно участвуют в накоплении органических соединений, гумусообразовании и накоплении азота в техногенных почвах, поскольку это единственная группа микроскопических растений, содержащих хлорофилл и увеличивающих органическую массу за счет фотосинтеза.

Водоросли выступают важным фактором преобразования стерильных грунтов в первичную почву, подготавливая условия для азотфиксирующих и ге- 